\section{Andriy Khokhlov, Lyudmila Khokhlova}

\title{
DEVELOPMENT OF BIOCARBON SORBENT FROM CORN WASTE WITH INCREASED DESTRUCTIVE ACTIVITY IN RELATION TO OIL
}

The object of research is the created bioactive sorbent based on biochar from corn waste for the purification of oil-contaminated natural environments. The expediency of using biochar from corn cobs as a matrix - a carrier of microorganisms-destructors of petroleum hydrocarbons in the production of biosorbent - has been substantiated. Biochar meets the requirements for oil sorbents - environmental friendliness, oil resistance ( $6-8 \mathrm{~g}$ of oil per $1 \mathrm{~g}$ of sorbent), manufacturability and biocompatibility. The porous structure and chemical nature of the surface partly determines the absorbency of the material, but the dominant factor is the interaction of the hydrophobic surface with petroleum hydrocarbons. A universal oil oxidizer - a microbial complex isolated from oil-polluted natural objects, in combination with a carbon carrier, is capable of neutralizing oil pollution of various types and concentrations. It has been established that microorganisms - oil-destructors, immobilized on the surface of the sorbent, are capable of decomposing almost all oil hydrocarbons. Microorganisms immobilized on a carbon material have a great potential for destructive action. During immobilization, the viability of microbial cells is maintained, and the effect of their use is significantly increased. The use of a bioactive carbon sorbent based on biochar and immobilized natural oil-oxidizing microorganisms of a wide spectrum of action allows one to localize oil pollution and neutralize it through biodegradation. The optimal parameters for obtaining an oleophilic sorption matrix based on biochar from corn waste and for growing microbial biomass with a high destructive activity for oil hydrocarbons have been established. The optimum pyrolysis temperature is $300-350^{\circ} \mathrm{C}$, the pyrolysis time is $25-30$ minutes. In this case, the sorption of oil obtained biochar reaches maximum values ( $6-8 \mathrm{~g}$ oil/gsorbent). Sufficient number

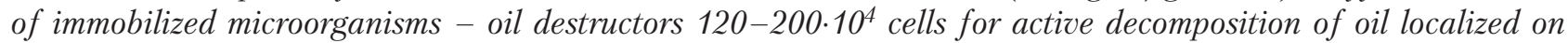
the sorbent surface. The operational characteristics of the obtained bioactive sorbents, technological features and methods of their use in cleaning the environment from oil pollution have been studied. The biosorbent does not require removal from the places of use and disposal. Cleaning of soils contaminated with oil and oil products has specific features and requires the use of agricultural techniques (loosening, moistening). The studies carried out have shown a change in the concentration of oil pollution in the soil from $40 \%$ to 1-5\% of oil in the process of biodegradation after 3 months at positive temperatures.

Keywords: biosorption complex, cellulose-containing raw materials, corn cob, biochar, oil-degrading microorganisms.

\section{Introduction}

The known methods of cleaning natural environments from oil pollution require an increase in their operational capabilities, their orientation towards a comprehensive solution to the problems of neutralizing oil pollution, regardless of environmental conditions. The existing technologies for the elimination of oil pollution of the natural environment using various sorbent materials, both natural and synthetic, in fact do not prevent environmental pollution, but are limited only to the removal of oil products.
Conventional sorbents create great difficulties in their application. Conglomerates of oil sorbents are difficult to collect from the surface of water or soil. In addition, conventional sorbents, if not completely removed, have a number of negative effects. This is the concentration of oil in the sorbent, where it lasts longer than usual.

Promising complex technologies using a new group of drugs - biosorbents, possessing not only absorption and physicochemical activity in relation to oil products, but also biological, that is, the ability to decompose oil due to biodegradation in a localized state on the surface of the 
sorbent. Destruction of oil can be carried out until the last stages, when only ecologically inert products of oil decomposition remain. The residual part of the biosorbent is the initial basis of the sorption material. The use of sorbents of this type will make it possible to quickly and effectively localize emergency oil and oil products spills and further ensure their complete decomposition.

It is important to obtain bioactive sorption materials based on raw materials of natural origin, bioactivated by a natural complex of oil-oxidizing microorganisms with a wide spectrum of action. The use of biosorbents is a technologically effective and environmentally friendly method of liquidating the consequences of accidental oil spills. As practice has shown, biosorbents can sometimes be the only means of combating emergency oil pollution for various types of environmental objects.

\section{The object of research and its technological audit}

The object of research is the created bioactive sorbent based on biochar from corn waste for the purification of oil-contaminated natural environments. The development of a technology for obtaining a biologically active environmentally friendly sorbent based on plant materials is a promising direction for eliminating oil pollution of water and soil. Carbon sorbents based on pyrolysate of cellulose-containing raw materials (biochar) among powdery sorbents of natural origin have a satisfactory absorption capacity with respect to oil and oil products of various compositions and, most importantly, are biocompatible. The use of corn cobs for biochar is due to the fact that its main chemical components are: cellulose, lignin and polysaccharides (pentosans and hectosans). The high content of cellulose and lignin in the structure of corn cobs is similar to wood in terms of content (Table 1), which makes it possible to obtain a similar carbon material in the pyrolysis process. Corn cobs do not contain resinous substances. Thus, obtaining a hydrophobic oil-absorbing carbon sorbent requires a special approach to the preparation of feedstock and the conduct of the pyrolysis process.

Table 1

Chemical composition of wood and corn cobs

\begin{tabular}{|c|c|c|c|}
\hline \multirow{2}{*}{ Components } & \multicolumn{3}{|c|}{ The percentages of the components } \\
\cline { 2 - 4 } & Pine & Dak & Corn cobs \\
\hline Cellulose & 41.93 & 44.17 & $30-34$ \\
\hline Lignin & 29.52 & 23.93 & $15-17$ \\
\hline Hexosans & 12.78 & 4.06 & $12-15$ \\
\hline Pentosans & 10.80 & 24.60 & $17-20$ \\
\hline Resin and wax & 3.17 & 0.68 & - \\
\hline Proteins & 1.27 & 1.62 & 1.58 \\
\hline Ash & 0.53 & 0.94 & 0.96 \\
\hline
\end{tabular}

The most important advantages of carbon materials are their durability and stability in aggressive environments, the ability to regulate the parameters of the porous structure in a wide range. Another advantage is the inertness of the surface, which eliminates the occurrence of unwanted side reactions. The biocompatibility of the material of the sorption matrix and microorganisms makes it possible to use biochar in ecological technologies. In addition, biochar meets the requirements for oil sorbents, namely, the sorbent must:

- absorb a significant amount of oil per unit weight;

- be non-toxic;

- do not violate the balance of natural ecosystems;

- have a relatively low cost and a sufficient raw material base.

The study of the adsorptive and destructive properties of a biosorbent based on pyrolyzed corn cobs with respect to oil samples of various genesis will determine the directions for the practical implementation of production technology and the use of effective environmentally friendly biosorbents for localizing oil pollution and its subsequent destruction. The optimal parameters of the synthesis of the oleophilic sorption matrix from corn cobs and the production of microbial biomass for its bioactivation with high destructive activity in relation to oil hydrocarbons have been established. Microorganisms-destructors, isolated from oil-polluted natural objects and adapted to various types of oil products, have an increased destructive ability with a wide spectrum of action. This fact determines the performance characteristics of bioactive sorbents. The priority direction is the use of environmentally friendly materials with natural affinity in environmental technologies. Renewable plant waste is precisely such materials.

\section{The aim and objectives of research}

The aim of research is development of a technology for producing a biosorbent based on pyrolysate of corn waste (corn cobs) with an immobilized natural consortium of oil-oxidizing microorganisms of high destructive capacity. To achieve this aim, it is necessary to solve the following tasks:

1. Establish the optimal technological parameters and techniques for the preparation of raw materials and the synthesis of an oleophilic sorption matrix from corn cobs, which has sorption activity in relation to oil and biocompatibility with oil-oxidizing microorganisms.

2. Isolate from natural oil-contaminated objects a consortium of microorganisms-destructors of hydrocarbons of a wide spectrum of action, which has stable synergism when returning to the environment, for bioactivation of the surface of the sorbent from corn cobs.

3. Determine the sorption and destructive activity of the biosorption complex on samples of oil products of various genesis.

4. Conduct laboratory tests of the effectiveness of the obtained biocarbon sorbent (biosorbent) from corn cobs.

\section{Research of existing solutions to the problem}

One of the directions for solving the problem of eliminating oil pollution is the use of biotechnologies that provide high cleaning efficiency $[1,2]$. Known microbiological preparations of powder and liquid origin, containing highly active microorganisms-destructors in a free or immobilized state. The use of biological products is limited, as a rule, by temperature conditions, the specifics of the object of pollution and high cost. The microbial preparations are not capable of localizing oil pollution, but only allow the 
destruction of oil [3, 4]. The advantages of using preparations based on varieties of local (aboriginal) microflora, adapted to specific soil and climatic conditions and selected taking into account the chemical composition of oil and oil products, are undeniable.

Biosorption materials localize oil pollution and ensure its degradation (decomposition). In addition, they do not create multi-kilogram conglomerates, as in the case of using supersorbents, which can't be collected from the surface of water or soil by any mechanical method [5, 6]. The use of biosorbents is a technologically effective and environmentally sound method of liquidating the consequences of accidental oil spills. Biosorbents are effective oil-absorbing sorbents, the surface of which is used as a carrier of microorganisms - oil destructors [3]. As practice has shown, biosorbents can sometimes be the only means of combating emergency oil pollution for various types of environmental objects. The biodegradation of oil takes place both on the surface under aerobic conditions and in depth, that is, under microaerophilic conditions. This effect is achieved by introducing aerobic and anaerobic microorganisms into the composition of biosorbents.

The well-known development called «microbial restoration of contaminated soils» [7] is based on the use of microorganisms that exist on the surface of pine bark and are naturally adapted to growth on complex hydrocarbons that are part of pine resin, as well as on the ability of the bark to absorb oil products. In this case, the concentration of oil is carried out due to sorption in the presence of microorganisms adapted to the degradation of substrates of this type. This is an example of the use of a natural sorbent and natural microflora.

The action of the biosorbent «Ekonadin» [8] is provided by the use of two strains of highly active bacteria - oil destructors, which are immobilized on a natural sorbent peat. The drug has a prolonged action. That is, when there is a nutrient medium (oil), biomass growth is induced; no oil - active growth stops. But the drug is active only at temperatures not lower than $10{ }^{\circ} \mathrm{C}$.

Also known is a sorbent based on aerosil containing microorganisms immobilized on the surface [9]. But such a sorbent is capable of biodegradation of oil only under aerobic conditions and is not environmentally friendly, which complicates its practical use. A biosorbent based on expanded perlite with immobilized microorganisms has a low destructive activity in relation to oil hydrocarbons [10]. Numerous studies have substantiated the need and prospects for the creation and use of effective biosorption materials with sorption, physicochemical properties and increased destructive activity in relation to petroleum products.

The use of carbon materials as a matrix for microorganisms in the creation of a petroleum biosorbent involves the study of the structural and surface properties of the initial sorption matrix and the bioactivated one. Carbon sorption materials based on vegetable cellulosecontaining raw materials occupy an important place among oil-absorbing sorbents of natural origin. They are cheap, environmentally friendly, efficient, and affordable. The raw material for obtaining such materials can be waste from the woodworking industry and agricultural waste. The properties of carbon sorbents are determined by both the nature of the feedstock and the conditions for their production by pyrolysis [11, 12]. Studies have shown that the immobilization of oil-oxidizing microorganisms on such a carbon matrix several times increases the destructive ability of microorganisms in comparison with other sorbents [13, 14].

\section{Methods of research}

The specific properties of the carbon material as an adsorbent are primarily determined by the porous structure, the main indicators of which are the pore volume and their size distribution. The chemical nature of the surface of the material also affects the adsorption properties of the material. Pyrolysis of cellulose-containing raw materials is the decomposition of the initial material (wood, plant residues) when heated to a certain temperature without air access, with the formation of gaseous (liquid) products, as well as solid residues - coal. The end product of complete pyrolysis of raw materials is almost pure carbon containing impurities of potassium, sodium, calcium, magnesium and iron oxides. Pyrolysis is based on a free radical reaction of thermal destruction of hemicellulose, cellulose and lignin, proceeding in accordance with 200-260, 240-350 and $250-400{ }^{\circ} \mathrm{C}$. Heat treatment at temperatures below $250{ }^{\circ} \mathrm{C}$ does not allow obtaining a stable porous structure. Heat treatment at temperatures above $400{ }^{\circ} \mathrm{C}$ leads to a slight decrease in the total volume and a change in the proportion of meso- and macropores in the total pore volume. The effectiveness of biochar in neutralizing contaminants depends on its surface area, pore size distribution and ion-exchange capacity. The physical structure and molecular composition of biochar can be critical for practical applications for soil and water. By its structure, biochar belongs to the class of carbonized substances, due to the commonality of their characteristic structural element. The structural element of a carbonized substance is an atomic network of polymer carbon. The atomic carbon networks in such a polymer are valently interconnected.

In laboratory conditions, the optimal modes of pyrolysate of raw materials were established to obtain highquality oil-absorbing carbon material used as a matrix for immobilization of oil-oxidizing microorganisms. Heat treatment of pre-prepared corn cob raw materials (crushing, screening, drying) in an oxygen-free atmosphere at a certain temperature regime makes it possible to obtain on its basis a carbon sorbent with specified properties relative to oil and petroleum products. During the process, the weight loss of the feedstock during heat treatment, bulk density and oil capacity (sorption capacity) of the resulting product were monitored. Since corn cobs do not emit resinous substances during pyrolysis, an additional treatment of the material with a water-repellent substance was carried out. Hydrophobization adds water resistance and moisture resistance to the material. Hydrophobization is applied to porous materials to increase their hydrophobicity. Compositions based on silicon compounds form the thinnest indelible film, imparting oil-absorbing properties in the pores and on the surface of the material. Organic silica compounds of the polyhydroxyloxane type in various dilutions were used as a surface water repellant to obtain a hydrophobic carbon material from corn cobs (Table 2).

Oil capacity depends on the time and temperature of pyrolysis (Fig. 1) and reaches values of $6-8$ goil $/ g_{\text {sorbent }}$ at the optimal pyrolysis temperature $-300-350{ }^{\circ} \mathrm{C}$, pyrolysis time $-25-30$ minutes. 
Table 2

Comparative structural and sorption characteristics of biochar based on corn cobs under hydrophobization conditions (pyrolysis temperature $350{ }^{\circ} \mathrm{C}$, pyrolysis time -30 min.)

\begin{tabular}{|c|c|c|c|}
\hline \multirow[b]{2}{*}{ The indicator } & \multicolumn{3}{|c|}{ The type of pyrolysate } \\
\hline & Pine & $\begin{array}{l}\text { Corn cobs } \\
\text { without liquid for } \\
\text { hydrophobization }\end{array}$ & $\begin{array}{c}\text { Corn cobs pro- } \\
\text { cessed by liquid } \\
\text { for hydrophobi- } \\
\text { zation }\end{array}$ \\
\hline $\begin{array}{l}\text { Hydrophobic- } \\
\text { ity, \% }\end{array}$ & $98-95$ & $20-30$ & 80-90 \\
\hline $\begin{array}{l}\text { Sorption capacity } \\
\text { with respect to } \\
\text { oil, } \text { goil }_{\text {oil }} \mathrm{g}_{\text {sorbent }} \\
\end{array}$ & $8.0-10.0$ & $2.0-3.0$ & $6-7.5$ \\
\hline $\begin{array}{c}\text { Static exchange } \\
\text { capacity, mg- } \\
\text { equ/g (SEC) }\end{array}$ & $3.2-5.1$ & $2.1-2.5$ & $2.2-2.9$ \\
\hline $\begin{array}{c}\text { Specific surface, } \\
\mathrm{m}^{2} / \mathrm{g}\end{array}$ & $60-80$ & $50-60$ & $45-65$ \\
\hline $\mathrm{Vs}\left(\mathrm{H}_{2} \mathrm{O}\right), \mathrm{sm}^{3} / \mathrm{g}$ & $0.08-0.10$ & $0.11-0.13$ & $0.07-0.09$ \\
\hline $\mathrm{Vs}\left(\mathrm{C}_{6} \mathrm{H}_{6}\right), \mathrm{sm}^{3} / \mathrm{g}$ & $0.09-0.12$ & $0.08-0.12$ & $0.07-0.11$ \\
\hline
\end{tabular}

Notes: Vs(C6H6) - porosity, pore volume, expressed as sorption on benzene; $\mathrm{Vs}(\mathrm{H} 2 \mathrm{O})$ - porosity, expressed by the pore volume of the sorption water; SEC - static exchange capacity

The operational properties of a biosorbent based on biochar from corn cobs, bioactivated by a natural consortium of oil-oxidizing microorganisms, are confirmed by the obtained surface and sorption characteristics. The assessment of the sorption capacity of the obtained carbon carrier in relation to the microbial culture was carried out according to the «specific sorption» and the fixation strength of the culture at the stage of intensive growth under standard conditions. The adsorption of biomass on the support ranged from 100 to $400 \mathrm{mg}$ of dry biomass per gram of sorbent. The binding strength of immobilized cells on the surface of the substrate was determined by desorption of cells from the surface of the carbon sorbent. Desorption was affected by up to $25 \%$ of microbial cells. On the surface of the carrier, an average of $76 \%$ of the immobilized microbial cells remained. Studies have shown that microorganismsdestructors immobilized on the surface of the sorbentcarrier do not change their activity for a long time (more than a year).

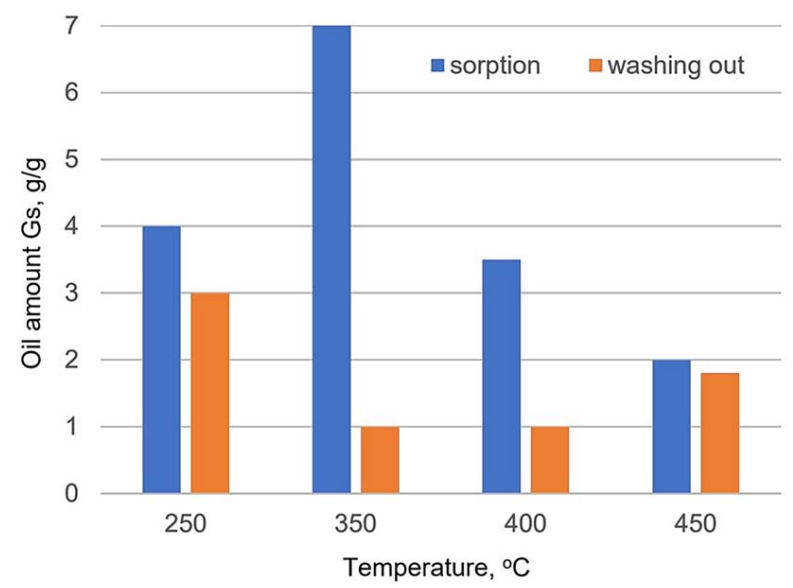

Fig. 1. Sorption properties of carbon sorbent from corn cobs at different pyrolysis temperatures
The evaluation of the decomposition of petroleum hydrocarbons under the action of a bioactivated sorbent from corn cobs was carried out using IR spectroscopy and gas-liquid chromatography.

The qualitative and quantitative indicators of the decomposition of hydrocarbons confirmed the conclusion that the potential of oil-oxidizing microorganisms is much higher if they are immobilized on the surface of the oil-absorbing sorbent.

\section{Research results}

The conducted studies have determined the characteristics of the porous structure of the carbon sorbent from pyrolyzed corn cobs. The sorbent is characterized by a polydisperse porous structure with different pores with a certain size range. The high hardness of the material was stated. Carbon sorbents based on pyrolysate of cellulosic raw materials are characterized by a polydisperse porous structure with various pores in a certain size range. A study of the programs of carbon sorbents using mercury porosimetry data revealed a slight decrease in the volume and specific surface area of mesopores $(2-50 \mathrm{~nm})$ and macropores $(>50 \mathrm{~nm})$ in the carbon sorbent from corn cobs and wood are almost the same (Fig. 2). The parameters of the raw material pyrolysis process are identical.

The nature of the immobilization of oil-oxidizing microorganisms on the surface of the carrier sorbent depends on the nature of the surface of the carbon material. As a result of carbonization of cellulose-containing raw materials, reactive groups are formed on the surface of the obtained biochar. The number of carboxyl and phenolic groups on the biochar surface determines the ability to hold biomolecules on the surface due to covalent bonds or groups $-\mathrm{COOH}-,-\mathrm{COCl}-,-\mathrm{NH}_{2}^{-},-\mathrm{NH}_{2}^{+}$.

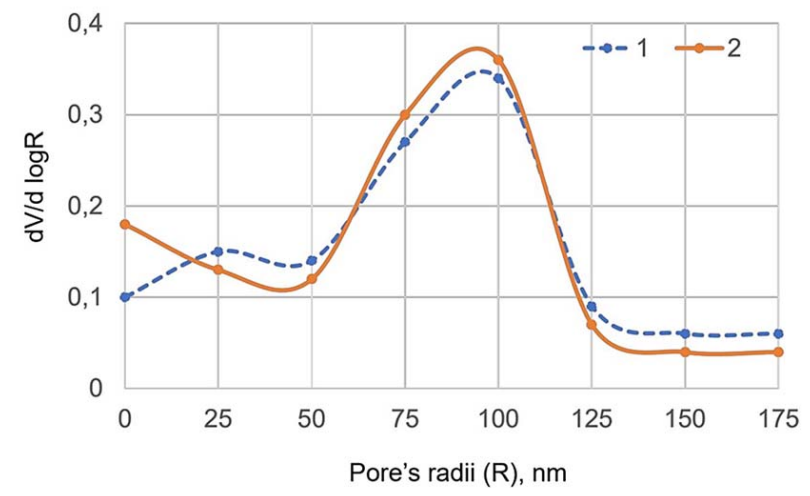

Fig. 2. Type of pores of carbon sorption material based on wood pyrolysate (1) and pyrolysate corn cobs (2)

IR spectroscopic studies of the carbon sorbent from corn cobs showed a decrease in the intensity of the bands (1200$1300 \mathrm{~cm}^{-1}$ ), responsible for the vibrations of phenolic groups, and the intensity of the bands $\left(1700-1750 \mathrm{~cm}^{-1}\right)$, characteristic of carboxyl groups during bioactivation of the primary sorption matrix.

In the process of bioactivation of the carbon material from corn cobs, the surface interaction of the sorption matrix with oil-degrading microorganisms occurs.

The change in the specific surface area and the amount of oxygen-containing functional groups during bioactiva- 
tion of the carbon sorption matrix is shown. The absorbed biomolecules are retained on the surface of the carrier due to van der Waals forces, hydrogen bonds, and hydrophobic interactions. The rate of microbial decomposition of oil localized on the surface of the sorbent was much higher than the biodegradation of a continuous layer of oil on the surface of the water (Fig. 3) with the identical amount of oil-oxidizing cultures $120-200 \cdot 10^{4}$ cells and oil (8 g) in the system.

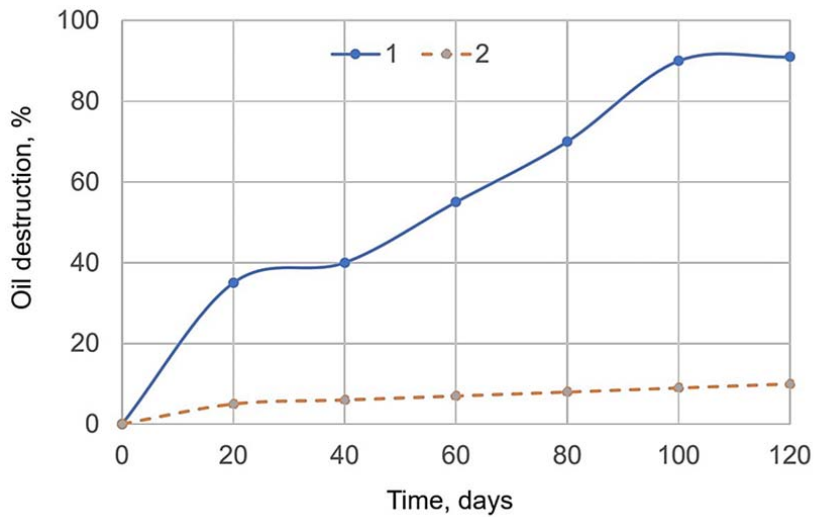

Fig. 3. Kinetics of oil destruction on the surface of water (1) and adsorbed on biosorbent (2)

The temperature of the medium affects the rate of decomposition of petroleum hydrocarbons and the composition of the products formed during biodegradation. The metabolic process is regulated by enzymes, which have different optimum temperatures. For most oil-oxidizing microorganisms, the optimum temperature for development is $25-30{ }^{\circ} \mathrm{C}$.

A universal oil-oxidizing microbial complex isolated from natural oil-contaminated objects, together with biochar from corn waste, is able to neutralize oil pollution of various types and concentrations. Evaluation of the destructive activity of the developed biosorbent in relation to petroleum products of various chemical composition showed the degree of destruction of more than $95 \%$. It was found that microorganisms - oil destructors, immobilized on the surface of the biosorbent, are capable of decomposing almost all oil hydrocarbons. The biooxidation rate decreases in the following order: diesel - crude oil - weathered oil - oil sludge - tar.

The expediency of an integrated approach to the elimination of oil pollution using a biosorption complex is shown, which ensures the localization of pollution due to effective sorption and its neutralization in a localized state due to active destruction. The use of plant raw materials and oil-decomposing microorganisms extracted from natural objects ensures the environmental safety of the use of an oil sorbent based on pyrolysate of corn cobs. On water surfaces biosorbent is used in quantities based on the calculation of the volume of oil. The technology of neutralization of oil products fixed on soil particles or on a hard surface (concrete, coatings) requires additional techniques. The use of a demulsifier in this case allows to extract oil products fixed on soil particles or any surface and create conditions for biodegradation.

\section{SWOT analysis of research results}

Strengths. The use of an environmentally friendly bioactive carbon sorbent of complex action based on the pyrolysate of corn cobs of immobilized natural varieties of oil-oxidizing microorganisms with a wide spectrum of action makes it possible to localize oil pollution and neutralize it as a result of biodegradation. The biosorbent does not require removal from the places of use and disposal, it is selfutilizing. An integrated approach to solving the problem of eliminating oil pollution by using a bioactive sorbent of a destructive type ensures the efficiency of work.

The production of biosorption material does not require expensive starting reagents and equipment. When receiving, cheap reproducible natural environmentally friendly raw materials are used.

Weaknesses. The cost price will only be adjusted during the production process. Calculation of economic parameters for a specific production will help reduce cash costs.

Opportunities. Further research can bring additional opportunities for the introduction of environmentally friendly biosorption material, presented not only for Ukraine, but also for objects in the near and far abroad.

Threats. The use of technology for cleaning oil-contaminated sandy soils at operating oilfield facilities using destructive biosorption complexes will undoubtedly lead to additional production costs. Changing existing practices and improving traditional methods of cleaning oil-contaminated objects, the introduction and use of fundamentally new scientific and practical results entail certain difficulties in organizing production.

\section{Conclusions}

1. The expediency of using a carbon sorption material based on pyrolysate of corn cobs as a matrix carrier of oil-oxidizing microorganisms in the production of biosorbent has been substantiated. First, the carbon material meets the requirements for oil sorbents - environmental friendliness, oil resistance, manufacturability. The sorption capacity of the obtained oil sorbent is $6-8 \mathrm{goil} / \mathrm{g}_{\text {sorbent }}$. Secondly, this material is biocompatible.

2. Studied the physicochemical and sorption properties of the original carbon sorption matrix and bioactivated. The porous structure and chemical nature of the surface partly determine the oil absorption of the material, but the dominant factor is the interaction of the hydrophobic surface with petroleum hydrocarbons due to hydrophobic non-polar groups.

3. Oil-oxidizing microbial complex isolated from natural oil-polluted objects, together with a carbon carrier, is capable of neutralizing oil pollution of various types and concentrations. Evaluation of the destructive activity of the developed biosorbent in relation to petroleum products of various chemical composition showed the degree of destruction of more than $95 \%$. The biosorbent does not require removal from the places of use and disposal.

4. Microorganisms-oil destructors, immobilized on the surface of the biosorbent, are capable of decomposing almost all oil hydrocarbons. The biooxidation rate decreases in the following order: diesel - crude oil - oil - oil sludge - tar. 


\section{References}

1. Andersson, B. E., Lundstedt, S., Tornberg, K., Schnürer, Y., Öberg, L. G., Mattiasson, B. (2003). Incomplete degradation of polycyclic aromatic hydrocarbons in soil inoculated with woodrotting fungi and their effect on the indigenous soil bacteria. Environmental Toxicology and Chemistry, 22 (6), 1238-1243. doi: http://doi.org/10.1002/etc.5620220608

2. Chernykh, M. S., Sadchikov, A. V. (2016). Oil destruction and bioremediation. Modern problems of science and education, 5. Available at: https://www.science-education.ru/ru/article/view?id=25214

3. Alonso-Gutiérrez, J., Figueras, A., Albaigés, J., Jiménez, N., Viñas, M., Solanas, A. M., Novoa, B. (2009). Bacterial Communities from Shoreline Environments (Costa da Morte, Northwestern Spain) Affected by the Prestige Oil Spill. Applied and Environmental Microbiology, 75 (11), 3407-3418. doi: http:// doi.org/10.1128/aem.01776-08

4. Abdel-Shafy, H. I., Mansour, M. S. M. (2016). A review on polycyclic aromatic hydrocarbons: Source, environmental impact, effect on human health and remediation. Egyptian Journal of Petroleum, 25 (1), 107-123. doi: http://doi.org/10.1016/j.ejpe.2015.03.011

5. Alexander, M. (2000). Aging bioavailability, and overestimation of risk from environmental pollutants. Environmental Science E Technology, 34, 4259-4265. doi: http://doi.org/10.1021/ es001069+

6. Sidheswaran, M. A., Destaillats, H., Sullivan, D. P., Cohn, S., Fisk, W. J. (2012). Energy efficient indoor VOC air cleaning with activated carbon fiber (ACF) filters. Building and Environment, 47, 357-367. doi: http://doi.org/10.1016/j.buildenv.2011.07.002

7. Deschamps, G., Caruel, H., Borredon, M.-E., Albasi, C., Riba, J.-P., Bonnin, C., Vignoles, C. (2003). Oil Removal from Water by Sorption on Hydrophobic Cotton Fibers. 2. Study of Sorption Properties in Dynamic Mode. Environmental Science \& Technology, 37 (21), 5034-5039. doi: http://doi.org/10.1021/es020249b

8. Haussard, M., Gaballah, I., Kanari, N., de Donato, P., Barrès, O., Villieras, F. (2003). Separation of hydrocarbons and lipid from water using treated bark. Water Research, 37 (2), 362-374. doi: http://doi.org/10.1016/s0043-1354(02)00269-5

9. Keith, A., Singh, B., Singh, B. P. (2011). Interactive Prim- ing of Biochar and Labile Organic Matter Mineralization in a Smectite-Rich Soil. Environmental Science E Technology, 45 (22), 9611-9618. doi: http://doi.org/10.1021/es202186j

10. Lehmann, J., Rillig, M. C., Thies, J., Masiello, C. A., Hockaday, W. C., Crowley, D. (2011). Biochar effects on soil biota - A review. Soil Biology and Biochemistry, 43 (9), 1812-1836. doi: http://doi.org/10.1016/j.soilbio.2011.04.022

11. Khokhlov, A., Khokhlova, L. (2018). Carbon Sorbent of Destructive Type Based on Wood Biochar for Removal of Oil Pollution. Journal of Environmental \& Analytical Toxicology, 8 (4), 576-583. doi: http://doi.org/10.4172/2161-0525.1000576

12. Somasundaram, S., Sekar, K., Gupta, V. K., Ganesan, S. (2013) Synthesis and characterization of mesoporous activated carbon from rice husk for adsorption of glycine from alcohol-aqueous mixture. Journal of Molecular Liquids, 177, 416-425. doi: http:// doi.org/10.1016/j.molliq.2012.09.022

13. Alcañiz-Monge, J., Pérez-Cadenas, M., Marco-Lozar, J. P. (2012) Removal of Harmful Volatile Organic Compounds on Activated Carbon Fibres Prepared by Steam or Carbon Dioxide Activation. Adsorption Science E Technology, 30 (6), 473-482. doi: http://doi.org/10.1260/0263-6174.30.6.473

14. Benhabib, K., Faure, P., Sardin, M., Simonnot, M.-O. (2010) Characteristics of a solid coal tar sampled from a contaminated soil and of the organics transferred into water. Fuel, 89 (2), 352-359. doi: http://doi.org/10.1016/j.fuel.2009.06.009

$\triangle$ Andriy Khokhlov, PhD, Senior Researcher, Department of Ecological Chemistry, Institute for Sorption and Problems of Endoecology of National Academy of Sciences of Ukraine, Kyiv, Ukraine e-mail:techsorb@ukr.net, techsorb@gmail.com, ORCID: https://orcid. org/0000-0001-5340-1869

Lyudmila Khokhlova, PhD, Senior Researcher, Department of Ecological Chemistry, Institute for Sorption and Problems of Endoecology of National Academy of Sciences of Ukraine, Kyiv, Ukraine, ORCID: https://orcid.org/0000-0002-2201-1312

$\triangle$ Corresponding author 